\title{
Why not common morality?
}

\author{
Rosamond Rhodes
}

\section{Correspondence to}

Dr Rosamond Rhodes, Medical Education, Icahn School of Medicine at Mount Sinai, New York, New York, USA;

Rosamond.Rhodes@mssm.edu

Received 18 June 2019 Revised 8 August 2019 Accepted 12 August 2019 Published Online First 11 September 2019

\section{Linked}

- http://dx.doi.org/10.1136/ medethics-2019-105878

- http://dx.doi.org/10.1136/ medethics-2019-105840

- http://dx.doi.org/10.1136/

medethics-2019-105826

- http://dx.doi.org/10.1136/

medethics-2019-105825

- http://dx.doi.org/10.1136/ medethics-2019-105799

- http://dx.doi.org/10.1136/ medethics-2019-105785

- http://dx.doi.org/10.1136/ medethics-2019-105936

\section{Check for updates}

(c) Author(s) (or their employer(s)) 2019. No commercial re-use. See rights and permissions. Published by BMJ.

To cite: Rhodes R.

$J$ Med Ethics

2019:45:770-777.

\section{ABSTRACT}

This paper challenges the leading common morality accounts of medical ethics which hold that medical ethics is nothing but the ethics of everyday life applied to today's high-tech medicine. Using illustrative examples, the paper shows that neither the Beauchamp and Childress four-principle account of medical ethics nor the Gert et al 10-rule version is an adequate and appropriate guide for physicians' actions. By demonstrating that medical ethics is distinctly different from the ethics of everyday life and cannot be derived from it, the paper argues that medical professionals need a touchstone other than common morality for guiding their professional decisions. That conclusion implies that a new theory of medical ethics is needed to replace common morality as the standard for understanding how medical professionals should behave and what medical professionalism entails. En route to making this argument, the paper addresses fundamental issues that require clarification: what is a profession? how is a profession different from a role? how is medical ethics related to medical professionalism? The paper concludes with a preliminary sketch for a theory of medical ethics.

\section{INTRODUCTION}

When I began work as a bioethicist at an academic medical centre, I felt secure that my knowledge of traditional moral and political philosophy provided me with the theoretical background for addressing moral problems in medicine. I uncritically accepted the reigning views of medical ethics as ethical theory applied to issues raised by technological advances in medical practice. Over the years however, I started to notice that the standard approaches did not fit with good clinical practice. One by one, counterexamples began to accumulate until I reached the conclusion that everyday ethics and medical ethics were incompatible.

That insight led me to conclude that a new theory of medical ethics was needed. I recognised that challenging long-standing and widely accepted views that medical ethics is nothing more than common morality applied to clinical matters would be contesting Beauchamp and Childress's 4-principle, ${ }^{1}$ Gert et al's 10-rule ${ }^{2}{ }^{3}$ and Jonsen et al's 4-topic ${ }^{4}$ approaches to medical ethics, in other words, committing heresy. Yet, faced with compelling evidence of how different medical ethics is from everyday ethics, the case had to be made. In this paper, I am setting aside bioethics orthodoxy and rejecting the common morality approach to medical ethics. I recognise that my opposition to this longstanding tradition requires a robust defence. Here, I present my case.

The problem may begin with terminology. In selecting 'bioethics' instead of 'medical ethics' as the title of the field, early authors lumped together issues of public policy, personal morality, and medical professionalism. Public policy matters are determined by reasons from common morality, whereas personal morality decisions reflect common morality but also largely turn on an individual's personal commitments and priorities. Issues of medical professionalism are different from both and require distinctly different reasons to support ethical conclusions. Overlooking those significant differences seems to have led to common morality approaches.

In what follows, I make a case for regarding the ethics of medicine as distinct and different from common morality and explain problems in the two leading common morality approaches to medical ethics. I focus on the work of Beauchamp and Childress and Gert et al because their theories have received the most attention over the past decades. Although there has been a good deal of criticism of their work, my remarks tack in a different direction. My aim is not to take issue with specific arguments but to show why common morality is untenable as an account of medical ethics.

\section{WHY A NEW APPROACH TO MEDICAL ETHICS IS NEEDED}

The dominant common morality view of medical ethics was articulated by K. Danner Clouser in his Encyclopaedia of Bioethics article on bioethics, where he explained that 'bioethics is not a new set of principles or manoeuvres, but the same old ethics being applied to a particular realm of concerns'. The strategy is further explained by Clouser and colleagues Bernard Gert and Charles Culver in Bioethics: a Return to Fundamentals (1997) and again in Bioethics: a Systematic Approach (2006), where they identify 10 moral rules as the crux of common morality. It is also the approach most prominently expounded by Tom Beauchamp and James Childress in their seven editions of Principles of Biomedical Ethics (1979-2013) and adopted by Albert Jonsen, Mark Siegler, and William Winslade in the eight editions of Clinical Ethics: a Practical Approach to Ethical Decisions in Clinical Medicine (1982-2015). In their books, Beauchamp and Childress argue that the action-guiding norms of traditional ethical theories converge on the set of common morality norms 'without argumentative support'. They identify the four principles of respect for autonomy, beneficence, non-maleficence and justice as the 'considered judgments that are the most well-established moral beliefs' to 'serve as an anchor of moral reflection' ${ }^{6}$ and use those principles to analyse ethical issues arising in medicine. In opposition to those accounts, I argue for recognising medical ethics as distinct and different from 
common morality, a position similar to stands taken by a handful of others. ${ }^{i}$

\section{ARGUMENTS FOR THE DISTINCTIVENESS OF MEDICAL ETHICS}

The common morality view that all bioethics is traditional ethics applied to novel circumstances amounts to a universal claim. It asserts that there is nothing distinctive about medical ethics and that all of medicine's ethics is explained by common morality. According to the laws of logic, a single counterexample refutes a universal claim. Because I am challenging the deeply entrenched and widely accepted view that medical ethics is just common morality, here are a week's worth of counterexamples.

1. Imagine someone sitting in a corner reading her newspaper and drinking her coffee. She has not assaulted anyone nor stolen anything, and has not inflicted harm on anyone. ${ }^{\text {ii }}$ To most observers, her behaviour would be totally acceptable. After all, the bulk of our moral responsibility in ordinary life is negative. We must refrain from harming others by not killing, stealing, injuring, or deceiving. Yet, a nurse ${ }^{\mathrm{iii}}$ who merely sits in a crowded emergency room or at a desk on a busy clinical floor doing the same would not be doing the right thing. That is because medical professionals have a positive duty to respond to patient needs and to actively promote their health.

2. In everyday life, people are free to make decisions anyway they like. You may choose to accept guidance from your horoscope, Tarot cards, a Crazy- 8 ball, or your favourite radio personality. You and your friends may decide on a movie by flipping a coin. You may rely on your gut feeling to select your vacation destination or relocate your family because you want a change. Medical professionals, however, are expected to rely on scientific evidence when they recommend treatment for patients. Gut feelings and the like are not acceptable justifications for medical decisions.

3. In the course of ordinary social interactions, we freely share what we know. We tell one another about what we see or hear and share what we discover about others. We convey information about who may be trusted to repay a loan, restaurants that serve bad food, or teachers who grade fairly. We tell one another about who is no longer speaking to whom, whose relationships are on the rocks, which medical professional was able to make a difficult diagnosis, and which dentist has bad breath. Information sharing is useful, entertain-

${ }^{\mathrm{i}}$ I count Hippocrates, Thomas Percival, John Gregory and more contemporary authors, including David Thomasma, Edmund Pellegrino, Bernard Baumrin, Robert Baker, Lance Stell and Lawrence McCullough, as allies in this cause. I also wish to point out that, in arguing for medical ethics as a distinctive field of morality, I reflect a point made by John Rawls in Political Liberalism. There Rawls notes that it is the distinct purposes and roles of the parts of the social structure ...that explains there being different principles for distinct kinds of subjects' (1993, p262). Seen from that perspective, perhaps every profession has its own moral rules and requires a distinctive character from its members. Exploring those questions, however, goes beyond the limited scope of this paper.

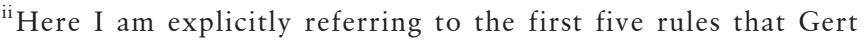
has informally identified as being from 'the first tablet'.

${ }^{\text {iii }}$ For simplicity, throughout this paper, I will be using physicians as my central example. I do, however, take the ethics of medicine to extend broadly and inclusively across all medical specialities and apply to all medical professionals, such as nurses, pharmacists, genetics counsellors, physical therapists, social workers, chaplains and bioethicists. Furthermore, I will be using 'doctor' and 'physician' as synonyms. ing, and part of the fabric of our lives. We are free to impart what we learn, and exceptions typically require explicit requests for keeping divulged information secret (eg, promises and non-disclosure agreements) or a special understanding arising from an intimate relationship. In medicine, at least since the time of Hippocrates, confidentiality is presumed, although some exceptions can be justified.

4. In ordinary life, we associate with whomever we choose. In fact, we learnt from our parents and teach our children to be careful in choosing our friends. We distinguish between people based on character and reputation, avoid those who might be a negative influence, and associate with people who are likely to be good role models. In medicine, however, medical professionals are supposed to be non-judgmental and to minister to every patient's medical needs without judgments as to their character or worth.

5. Most people today consider sexual activity among consenting adults to be ethically acceptable. Unless force, deception or indecent exposure is involved, adult sexual interactions are typically unobjectionable. In medicine, however, consent does not legitimise a physician's sexual involvement with a patient. We expect a patient's invitation for a tryst to be declined and that none would be issued to a patient by a medical professional.

6. In social situations, asking probing personal questions is regarded as rude. I have heard that in Texas and Oklahoma, you should never ask a man how much money or how much land he has. We should not inquire about the details of other people's sex lives, their constipation, their drug use, or even their weight. Many people do not speak about death, or illness, or emotions, and many people studiously avoid discussion of politics. Yet, taking a complete and detailed patient history can include asking about a patient's diet, bowel habits, sexual practices, drug use, previous illnesses, emotions, and fears.

7. The morality of ordinary life requires us to regard other adults as autonomous and to respect their choices. Immanuel Kant instructs us to 'cast a veil of philanthropy over the acts of others'. This injunction amounts to a demand that we regard the acts of others as if they were chosen with thoughtful consideration. For the most part, Kantian respect commands us to leave others alone and to allow them to act as they choose. Even medical professionals observe this rule when they are outside of their clinical setting. When they see others smoking cigarettes, they walk by with respectful disregard even though they think of cancer risks. They remain silent when they observe people with multiple tattoos or items of body piercing jewellery, as they register concern for hepatitis. They say nothing when they see overweight people indulging in decadent deserts, although they are sensitive to dangers of obesity. Nevertheless, it is hard to imagine that a good medical professional would fail to admonish a patient about cancer risks, hepatitis, or obesity during an office visit. Physicians are not allowed to presume that patients are acting autonomously when they appear to be making poor health choices. Instead, they are responsible for vigilant assessment of patients' decisional capacity and are sometimes required to oppose patients' stated preferences (eg, refusal of surgery for a strangulate hernia or ruptured appendix out of fear of being invaded by aliens). Even though medical professionals describe their first-line interventions to address poor decisions as education (eg, repetition and extra visits, including relatives in discussions), those measures should be recognised as the paternalistic interventions that they are. 
Table 1 The distinctiveness of medical ethics

\begin{tabular}{|c|c|c|}
\hline Counterexamples & Duties of medical ethics & ethics \\
\hline 1. Look after your own interests. & Act for the good of patients and society. & A moral ideal is transformed into a duty. \\
\hline 2. Make choices your own way. & Base decisions on scientific evidence. & A moral ideal is transformed into a duty. \\
\hline 3. Share information. & Confidentiality. & Permissible behaviour is impermissible. \\
\hline 4. Judge the worth of others. & Non-judgmental regard. & Permissible behaviour is impermissible. \\
\hline 5. Enjoy sexual interaction. & Non-sexual regard. & Permissible behaviour is impermissible. \\
\hline 6. Mind your own business. & Probe (with examination, tests and questions). & Impermissible behaviour is a duty. \\
\hline 7. Presume others have autonomy. & Assess decisional capacity. & Impermissible behaviour is a duty. \\
\hline
\end{tabular}

These examples make the point that medical ethics is distinct and different from common morality. To summarise the differences that the counterexamples illustrate, table 1 makes the dissimilarities glaring and explicit. This graphic depiction of the difference between the duties of medical ethics and common morality highlights our different expectations for the behaviour of medical professionals and non-physicians.

If common morality and medical ethics were the same, then the ethically justified behaviour for medical professionals and everyone else would be the same. However, as the table illustrates, they are not. If common morality explained medical ethics, logically, the same premises would lead to the same conclusions for everyone. The marked differences in what is optional for ordinary people and required for medical professionals, and the radical differences in what is acceptable and unacceptable for medical professionals and others demonstrate that the ethics of everyday life is significantly different from the ethics of medicine in dramatic and important ways.

If any of my examples of the difference between common morality and medical ethics is persuasive, then either the situations are different for medical professionals and others in an ethically significant way or the principles involved are different, or both. As I see it, the facts that the actions are performed by a medical professional in a professional context are significant differences that go a long way towards explaining the moral differences. This implies that medical professionals should not rely on common morality to guide their practice or to resolve their ethical dilemmas. Instead, they should be governed by standards of medical ethics and professionalism.

In addition, it is hard to see how the different duties of ordinary people and medical professionals could be explained by invoking the 4 principles or the 10 rules because those common morality concepts do not figure into explaining professional duties. Reasons that are specific to medical practice explain those specific duties, making common morality largely irrelevant in my examples. In other words, common morality does not account for why medical ethics requires non-judgmental regard, non-sexual regard, confidentiality or the rest. This suggests that different or additional moral factors are involved in the ethics of medicine.

Beauchamp and Childress, as well as Gert et al do speak of circumstances, such as professions, in which moral ideals are transformed into duties. They never explain why or how that significant transformation occurs, or how aspirational behaviour becomes a strict obligation. They offer no account of when and how the transformation is accomplished, no rationale to justify and explain those radical changes, and persist in maintaining that common morality is doing the explanatory work. However, in the absence of a robust explanation of how the same premises lead to contradictory conclusions for medical professionals and others, we should recognise that common morality is not consistent with medical ethics.

\section{WHY MEDICAL ETHICS IS NOT COMMON MORALITY Beauchamp and Childress}

Even though the distinction between common morality and medical ethics is hardly mentioned in their analyses, early on in their book, Beauchamp and Childress do suggest that there are 'particular moralities', including 'professional moralities', that vary from common morality. They also accept that some ideals of common morality become requirements for people in professions 'by their commitment to provide important services to patients, clients, or consumers'. ${ }^{8}$ While they state that 'professional roles engender obligations that do not bind persons who do not occupy the relevant professional roles', ${ }^{9}$ they never explain what that commitment is, how it comes about or what the specific obligations are. Granting that moral ideals can become demands of the moral life and that '[s]pecial roles and relationships in medicine require rules that other professions may not need', ${ }^{10}$ they nevertheless follow Jay Katz in dismissing the value of medicine's 'visionary codes of ethics'. ${ }^{11}$

Yet, in the section 'Negligence and the Standard of Due Care' in chapter 5, 'Nonmaleficence', Beauchamp and Childress list four essential elements of negligence that define violations of the responsibility to exercise due care:

1. The professional must have a duty to the affected party.

2. The professional must breach that duty.

3. The affected party must experience harm.

4. The harm must be caused by the breach of duty (emphasis added.$^{12}$

All of that sounds plausible, as far as it goes, but the central explanatory element in Beauchamp and Childress's approach is missing, namely, the account of what medical professionals' duties are and why they are duties for those who join the profession. Without enumerating, justifying and explaining medical obligations, the requirements of duty are left unspecified. That lacuna invites disagreements and breaches of duty because physicians can legitimately claim ignorance of being bound by duties that they have not recognised.

Beauchamp and Childress recognise that the vagueness of their four principles ${ }^{\text {iv }} 13$ leads to inconsistency and actually

\footnotetext{
${ }^{\text {iv }}$ In this more recent paper, Beauchamp expands his list of conceptual tools from the four principles by adding a list of 10 'universal rules of obligation' and some 'universal virtues' and 'universal ideals'. Nevertheless, he still maintains that particular moralities such as professions 'share the norms of common morality with all other justified particular moralities' [italics in the original] (Beauchamp 2014, p34). In other words, Beauchamp holds fast to his view that professional ethics is derived
} 
embrace the inevitable resulting disagreement, declaring that they remain sceptical of the possibility of providing 'a unified foundation for ethics. ${ }^{14}$ In the 2009 sixth edition of Principles of Biomedical Ethics, they unambiguously express their acceptance of that result, stating, 'we regard disunity, conflict, and moral ambiguity as pervasive features of the moral life that are unlikely to be eradicated by moral theory. ${ }^{15}$ Whereas acceptance of the resulting variety of views may be a virtue in the politics of a liberal pluralistic society, leaving individual medical professionals to interpret, specify and generalise in decisions on common questions of medical ethics can be problematic. The resulting 'untidiness, complexity, and conflict' ${ }^{15}$ may be tolerable or even advantageous in public debates and academic ivory towers, however, patients need to know the parameters of what is reasonable to expect from physicians and medical professionals need at least clear signposts for navigating the complicated terrain of clinical practice.

\section{Gert et al}

Similarly, Gert et al maintain that their 10 rules of common morality provide an account of medical ethics. They would assert that the 'moral ideals' of preventing death, pain, disability, loss of pleasure and loss of freedom go a long way towards explaining my examples. ${ }^{16}$ However, the transformation from an ideal of beneficence to a strict duty or, in Kantian terms, from an imperfect to a perfect duty is a significant difference and is not easy to explain. Also, the application of common morality rules to my seven examples requires a good deal of unpacking and justification. Expecting medical professionals to integrate and analyse the implications of the 10 rules is burdensome and perilous. It is more reasonable and efficient to enumerate and explain the duties that medical professionals should uphold.

Gert et al would also argue that their seventh rule, 'Keep your promise, ${ }^{17}$ explains the responsibilities of physicians in my examples. Whereas that rule might account for a moral ideal becoming a stringent moral requirement for someone who makes a promise to uphold it, I do not see how promising radically changes the content of moral responsibility from something to its opposite when the conclusion is supposed to be derived from the same rules.

The radical differences could be explained by medicine's distinctive duties, and their tenth rule does require people to 'Do your duty'. ${ }^{17}$ While they do recognise that professions have 'particular moral rules and special duties', they regard that difference as merely a matter of 'culture'. ${ }^{18}$ Indeed, they maintain that,

\begin{abstract}
Many of the duties of a profession are particular applications of the general moral rules (which are valid for all persons in all times and places) in the context of the special circumstances, practices, relationships and purposes of the profession. Thus, the duties are far more precise with respect to the special circumstances characterizing a particular domain or profession (emphasis added). ${ }^{19}$
\end{abstract}

In other words, they persist in their assertion that the rules of everyday ethics explain professional ethics. Aside from granting that changes in responsibility are 'largely set by the medical profession, though perhaps clarified and modified by law and society', ${ }^{20}$ they say little to explain how medical

from common morality and is nothing more than narrowly specified conclusions from common morality. professionals become bound to conform with professional duties that are diametrically opposed to what others should do.

It appears that Gert and colleagues never appreciate that responsibility to assess patients' decisional capacity is a problem for their common morality approach to medical ethics. Their rules four and five prohibit deprivations of freedom or pleasure, ${ }^{21}$ but they provide numerous examples illustrating medical professionals' duty to assess decisional capacity. For example, they describe an elderly depressed woman who lost a great deal of weight. She understands and appreciates her life-threatening situation and acknowledges that an irrational fear keeps her from consenting to the electroconvulsive treatment that she knows is likely to cure her depression. ${ }^{22}$ They therefore conclude that the woman lacks decisional capacity, and electroconvulsive treatment should be administered over her objection. Their astute analysis of medical paternalism demonstrates that they regard assessment of decisional capacity as a medical responsibility. It should be noted, however, that acknowledging physicians' duty to assess capacity and to paternalistically protect patients from harm opposes common morality responsibilities to avoid deprivation of freedom or pleasure. Although I fully agree that medical professionals have the duty that the authors ascribe to them, the duty to assess decisional capacity is clearly at odds with their rules, and it cannot be derived from common morality.

Their common morality approach also leaves Gert et al with a peculiar position on euthanasia. They see physicians as being obliged by common morality with at least as much stringency as others are. Then, because 'do not kill' is a rule of common morality, ${ }^{21}$ and because they consider 'preventing death' to be a 'moral ideal', ${ }^{23}$ they are hard pressed on how physicians should respond to requests from 'competent patients who rationally prefer to die'. ${ }^{24}$

So, what to do? They opt for dancing a little sidestep and leaping into specious equivocation. They write, 'Not treating counts as killing only when there is a duty to treat; in the absence of such a duty, not treating does not count as killing. ${ }^{24}$ They go on to maintain that 'if a competent patient rationally refuses treatment, abiding by that refusal is not killing. ${ }^{25}$ But only pages earlier in the book, they hold that there is no moral distinction between refusing, withholding and withdrawing treatment. ${ }^{26}$ Yet, they insist on describing the removal of life-preserving treatment as abiding by a competent patient's current or previous wishes, and not as killing.

If a non-physician with no duty to treat anyone walked into a patient's room and disconnected the patient from a ventilator and death resulted, she would be charged with murder because what she did was killing even if it was acting in accordance with the patient's request. It is hard to see how the very same act could be both killing and not killing. Such acts are killing because of the link between breathing and life and because of the dependency of the individual who dies. The only way that Gert and colleagues avoid recognising these incontrovertible facts is by pretending that medical professionals are not doing what they are obviously doing and claiming that they are really only abiding by a competent patient's rational request. Really, they are doing both, abiding by the patient's request and killing him.

It is, however, conceivable that an act forbidden for most people may be permitted when performed by someone who is allowed to do it. An army infantryman may be justified in shooting people when others are not. A police officer may be justified in imprisoning people when others are not. Likewise, a physician may be justified in administering poisons (eg, chemotherapy), cutting into another's body and removing tissue (ie, 


\begin{tabular}{ll}
\hline Table 2 & Some distinctive features of medicine \\
\hline Knowledge & Anatomy, physiology, immunology, pathology, pharmacology, genetics, microbiology, genomics and biochemistry \\
\hline Powers & Determine lack of decisional capacity; impose treatment over objection; deprive people of freedom (ie, involuntary commitment). \\
Privileges & $\begin{array}{l}\text { Ask probing questions; examine nakedness; image inside; prescribe and administer medication (ie, poison) or treatment; perform } \\
\text { surgery (ie, assault with deadly weapons); inflict pain. }\end{array}$ \\
Immunities & From prosecution for employing powers and privileges; from prosecution for untoward outcomes. \\
\hline
\end{tabular}

performing surgery), and even killing (ie, performing euthanasia) when others are not. Because society authorises such professionals to wield special powers, privileges and immunities, they are allowed to perform those extraordinary acts. There is no obvious reason to presume that the rules which govern professional licences are the same as common morality. In fact, when people in the military kill, and when police deprive people of freedom, they are likely to be performing their duty. Similarly, when physicians cause pain (eg, in an examination), disable (eg, in an amputation) and kill (eg, in a high-risk, potentially life-saving surgery), they are likely to be performing their duty. Without recognising that the moral rules of professions are radically different from common morality, we end up in confusion. A simpler and more honest approach involves accepting that professional ethics involves departures from common morality.

\section{ROLES AND PROFESSIONS}

Although common morality advocates casually acknowledge that professional responsibility is somehow involved in medical ethics, they pointedly deny its centrality. They also fail to distinguish social and institutional roles from professions. ${ }^{v} 27$ Role morality is consistent with common morality, and special rolerelated obligations (eg, being a parent, butcher, baker or candlestick maker) derive from individuals' voluntarily assuming special responsibilities by making an explicit or implicit promise. ${ }^{\mathrm{vi}} 28-33$ The starting point for recognising that medicine requires its own distinctive morality lies in appreciating that medicine is not a role but a profession and what that means.

Social scientists define professions by describing what they see. For example, sociologist Talcott Parsons observes that professions involve 'a cluster of occupational roles, that is, roles in which the incumbents perform certain functions valued in the society', and that they typically provide a livelihood and have their own codes and oaths, their own technical language and sometimes their own uniforms. ${ }^{\text {vii }} 3435$ All of that is interesting, but then we should consider why that is so.

Professions are different from roles in that the knowledge, powers, privileges and immunities that society allows for professions are radically different from what is allowed for ordinary citizens. Some of the commissions granted to professionals, and no one outside of those professions, are listed in table 2. Because they are potentially dangerous, ${ }^{\text {viii }} 3637$ the duties of each profession must be articulated and the limitations on how their distinctive authority may be employed must be delineated and explained.

Whereas any adult may take on duties of parenthood, butcher his own meat, bake her own cakes, and make his own

\footnotetext{
${ }^{\mathrm{v}}$ In the ethics literature, roles and professions are often lumped together.

${ }^{\text {vi } R o l e ~ m o r a l i t y ~ a n d ~ ' v o l u n t a r i s m ' ~ a r e ~ d i s c u s s e d ~ b y ~ n u m e r o u s ~}$ authors.

vii Sociologists like Talcott Parson define 'profession' by cataloguing what they observe about professions.

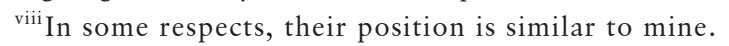

candlesticks, only medical professionals are permitted to perform surgery, only those in the military may explode bombs to kill other humans, and only priests may grant absolution. ${ }^{\text {ix }}$ In order to be trusted with the remarkable freedom that society allows its members, each profession (eg, medicine, military and clergy) must publically articulate its own profession-specific moral rules for managing those extraordinary liberties and describe the distinctive professional character required from its members.

\section{THE INCOMPATIBILITY OF COMMON MORALITY AND MEDICAL ETHICS}

Thus far, I presented examples showing that common morality does not explain medical ethics and identified significant shortcomings with both the Beauchamp and Childress and the Gert et al common morality accounts of medical ethics. Taken together, the argument leads to the conclusion that medical ethics requires a different theory to explain medical professionals' distinctive responsibilities. In the examining room and at the bedside, patients expect medical professionals to uphold standards of medical professionalism and display character traits and attitudes that go beyond requirements of common morality. Without being able to rely on clinicians cleaving to the standard of care, being non-judgmental, respectful, caring, upholding confidentiality, maintaining professional competence, regulating the profession, and fulfilling their additional distinctive responsibilities, patients would have to be guarded and sceptical in their interactions with medical professionals, undermining the good that medicine can provide. And without clearly articulated duties, medical professionals are left without a rudder to struggle through ethical issues when better moral guidance should be provided.

\section{MEDICAL PROFESSIONALISM}

Over the past 20 years or so, there has been considerable discussion of medical professionalism. Several authors who discuss professionalism recognise that something akin to a social contract is involved and that trust is necessary for the practice of medicine. Yet, there has been some disagreement within the academic medicine and medical education communities about what medical professionalism is ${ }^{38-44}$ and how it should be incorporated into medical training. ${ }^{45-48}$ Some argue that professionalism is about rules ${ }^{49-52}$; others maintain that it is about virtues, character or beliefs ${ }^{53-56}$; and others hold that it is about achieving (measurable) competencies. ${ }^{57-60}$ The disagreement is understandable because professionalism is a complex amalgam of all these elements.

The critical point that has not been adequately appreciated is that the concept of medical professionalism is derived from the distinctive

${ }^{\mathrm{ix}}$ Exploring the details of how and why professional identity should be distinguished from roles goes beyond the limited scope of this paper; it is a project for another day. For the purposes of this paper, it is enough to enumerate the extraordinary ways in which license granted to medical professionals exceeds what other individuals may do. 
ethics of medicine. Professionalism is needed because it commits medical professionals to ethical standards that are different from and more demanding than those of common morality. It requires physicians to understand what the distinctive duties of medicine are, how they apply to medical practice, and why physicians must uphold those duties. It entails medical professionals embracing their unique obligations, identifying with them, and accepting the responsibility to fulfil them with a sincere commitment. In that sense, it involves developing a character that takes pleasure in fulfilling professional obligations and a commitment to moderating desires that might interfere with upholding professional duties. In sum, professionalism is medical professionals' personification of medical ethics. Professionalism involves understanding the obligations of a physician, making oneself into a person who is likely to fulfil those duties and acting in accordance with the dictates of medical ethics. The hallmark of medical professionalism is the commitment to and the internalisation of medicine's distinctive ethics. Because medical ethics is radically different from common morality, it has to be inculcated and policed by the profession.

\section{WHY MEDICINE NEEDS ITS OWN ETHICS}

A survey of codes and statements of medical ethics reveals the obvious, that they differ significantly in length and detail. Although there is a good amount of overlap in their content, there are also stark disagreements in positions on important issues. When a medical society's code makes claims that are internally inconsistent, and when different statements of medical ethics are inconsistent with each other, the variation suggests that a theory of medical ethics is needed.

One way to begin formulating a theory is by employing a thought experiment and seeing what follows. ${ }^{\mathrm{x}}$ In this case, we can begin by imagining how medicine came about and see what we can learn from the exercise.

Imagine people in early civilisations who were aware that they and their loved ones could suffer injury or succumb to disease. They wanted guidance for avoiding those conditions and help in addressing the consequences, such as pain, disability and death. They therefore allowed a group, called them medical professionals, ${ }^{\mathrm{xi}}$ to develop the knowledge of fields we now call anatomy, physiology, and pharmacology, and to develop examination and surgical skills. To enable medical professionals to accomplish the goals of using their special knowledge and skill in meeting the needs of people in their communities, societies granted medical professionals powers, privileges and immunities permitted to no one else. Medical professionals' powers included the authority to quarantine people to prevent the spread of infectious disease, to decide that someone lacks decisional capacity, to impose treatment on him over his objections, and to determine death. Medical professionals' privileges allow them to ask strangers to undress, concoct and administer substances that may be poisonous, and to perform surgery. Moreover, medical professionals' immunities protect them from punishment for exercising their extraordinary powers and privileges or causing harm (eg, disability or death) with their efforts.

Because the knowledge, skills, powers, privileges and immunities allowed to medical professionals and no one else are potentially dangerous, society demands clear standards demarcating how medical professionals' exclusive license may be employed. ${ }^{\text {xii }}$

\footnotetext{
${ }^{x}$ Philosophers call this the hypothetico-deductive method.

${ }^{x i}$ They have also been called priests, shamans, and medicine men.

${ }^{x i i}$ Here I am distinguishing professional ethics from both common morality and what has been called 'role morality'. It is
}

\section{Box 1 The duties of medical ethics}

- Seek trust and be deserving of it.

- Use medical knowledge, skills, powers, privileges and immunities for the benefit of patients and society.

- Develop and maintain professional competence.

- Provide care based on need.

- Be mindful in responding to medial needs.

- Base clinical decisions on scientific evidence.

- Maintain non-judgmental regard towards patients.

- Maintain non-sexual regard towards patients.

- Maintain the confidentiality of patient information.

- Respect the autonomy of patients.

- Assess patients' decisional capacity.

- Be truthful in your reports.

- Be responsive to requests from peers.

- Communicate effectively.

- Police the profession.

- Assure justice in the allocation of medical resources.

As physician Edmund Pellegrino appreciated, doctors must publicly proclaim acceptance of the duties of medical ethics. ${ }^{61}$ It is also imperative for medical professionals to demonstrate their commitment to using their distinctive dispensations exclusively for the benefit of patients and society and observing professional limitations on their behaviour so that they can be trusted. Together, the public declaration and a history of behaviour constrained by medical ethics enable society to trust medical professionals wielding their extraordinary prerogatives.

Because people with medical needs make themselves vulnerable by trusting medical professionals and medical institutions based on their professional status, the first and fundamental duty of medical ethics must be to seek trust and be deserving of it. The second duty of medical ethics constitutes medicine's fiduciary responsibility, that medical professionals must use their medical knowledge, skills, powers and privileges for the benefit of patients and society. Several specific duties of medical ethics follow from medical professionals' foundational duties. Those more specific duties are justified as necessary means to achieve or maintain trust. Thus, medicine's foundational duties generate the moral force behind the additional duties and inform medical professionalism. Box 1 presents my list of the duties of medical ethics. Although some items on the list may be subdivided and some additional duties may be relevant for specific domains of clinical practice, the duties enumerated below identify the core responsibilities of the profession.

Medical professionals are the ones who define professional duties because they are the only ones who adequately understand what is involved, appreciate potential risks and benefits of their services, and distinguish competent practice from unacceptable performance. Therefore, the ethics of medicine is internal to the profession: it is constructed by the profession and for the profession, and needs to be continually critiqued, revised and reaffirmed by the profession.

Every rule has exceptions. That said, any moral system that involves more than a single principle, rule, or duty inevitably confronts the problem of moral conflict. Moral conflicts arise when two or more cherished values are relevant considerations but point

because a profession is permitted special powers, privileges and immunities that it requires distinctive rules for the regulation of those distinctive powers, privileges, and immunities. 
to different and incompatible actions. In many cases, one duty will have to be sacrificed in order to uphold another, and different medical professionals may have different views on how to proceed. Morality requires making difficult judgments, taking responsibility for them and living with the uncertainty of not knowing if you made the right call. Furthermore, because so much medical care involves multi-disciplinary teams of professionals working together, teams need to arrive at a consensus on how to proceed. They need guidance for thinking through the ethical quandaries that arise in clinical practice, tools to aid them in navigating medicine's challenging moral terrain, and opportunities to develop competence in thinking through these decisions. ${ }^{62}$

\section{CONCLUSION}

In his prescient article, 'The Autonomy of Medical Ethics: Medical Science vs Medical Practice', Bernard Baumrin explains what makes a field of knowledge autonomous. He writes,

\begin{abstract}
In philosophic circles such a question is usually put this way: is such and such domain or subject matter autonomous? In professional circles the language tends to be more metaphorical: is this or that subject matter merely an offshoot of some more fundamental study? ... To say that such and such a subject is something on its own and not reducible to something else, some other intellectual endeavor, is to say it is an autonomous subject, and that means it is not fully reducible to some other subject, like metallurgy to chemistry, botany to biology, or even chemistry to physics. One domain is reducible to another ... if its principles or theorems are deducible from the other domain. ... [F]or the independence of some domain to be established there needs to be at a minimum a species of data sui generis to it. This, along with principles specific to the domain (ie, not deducible from any other domain) establishes the autonomy of the discipline. .iii 6364
\end{abstract}

In this sense, I have argued that medical ethics is an autonomous field. It is precisely because medical professionals' duties are not derived from precepts of common morality or any other field and because they cannot be deduced from common morality that medical ethics is an autonomous field. As an independent moral domain, the foundational commitments of the profession and the specific requirements of medical ethics have to be defined and explained.

In this discussion, I have made the case for disengaging medical ethics from common morality. I have also suggested that medical ethics provides the core and substance of medical professionalism. What remains for another project is to articulate, explain and justify the specific duties and virtues that constitute medical ethics, to define how they direct medical professionalism, and to illustrate the profession's distinctive duties with examples that help medical professionals understand their professional obligations and illustrate how they may be fulfilled. Such a theory of medical ethics must cohere with the laudable elements of clinical practice, explain why they are correct, and elucidate why some commonly accepted behaviours are unacceptable.

Correction notice This article has been corrected since it was first published online. Footnotes viii and xiii were added.

Acknowledgements The argument that medical ethics is distinct and different from common morality is developed and spelled out in greater detail in my forthcoming book. Also, the tables that appear in this article are featured in my forthcoming book. The Trusted Doctor: Medical Ethics and Professionalism, Oxford University Press, 2020. I am grateful to Robert Baker and those who asked

\footnotetext{
xiii In presenting his argument, Baumrin is following philosopher G.E. Moore's example of arguing that ethics is an autonomous field and distinct from fields such as biology and physiology.
}

thoughtful questions when I presented this material at the Cambridge Consortium for Bioethics, Paris, France, on 28 June 2019, for pressing me to refine my thoughts on the issues discussed in this paper.

Contributors I am the sole author of this paper.

Funding This research received no specific grant from any funding agency in the public, commercial or not-for-profit sectors.

Competing interests None declared.

Patient consent for publication Not required.

Provenance and peer review Not commissioned; externally peer reviewed.

\section{REFERENCES}

1. Beauchamp TL, Childress JF. Principles of Biomedical Ethics. 7th edition. New York: Oxford University Press, 2013.

2. Gert B, Culver CM, Clouser KD. Bioethics: A Return to Fundamentals. New York: Oxford University Press, 1997.

3. Gert B, Culver CM, Clouser KD. Bioethics: A Systematic Approach. New York: Oxford University Press, 2006.

4. Jonsen AR, Siegler M, Winslade WJ. Clinical Ethics: A Practical Approach to Ethical Decisions in Clinical Medicine. 8th edition. McGraw-Hill Education, 2015.

5 Clouser KD. Bioethics. In: Reich W, ed. Encyclopedia of Bioethics. 1st edition. New York: The Free Press, 1978: 532-42.

6. Beauchamp and Childress 2013:407-8.

7 Kant I. The Metaphysical Principles of Virtue, (Part II of The Metaphysics of Morals). In: Ellington JW, ed. Immanuel Kant: Ethical Philosophy. Indianapolis: Hackett Publishing Company, 1993.

8. Beauchamp TL, Childress JF. Principles of Biomedical Ethics. 7th edn. New York: Oxford University Press, 2013: 7. 7.

9. Ibid. p. 46

10. Ibid. p. 6 .

11. Ibid. p. 8.

12. Ibid. p. 155.

13 Beauchamp T, Gordon J, Renteln J. "The compatibility of universal morality, particular moralities, and multiculturalism". In: Teas W, Renteln AD, eds. Global Bioethics and Human Rights. Plymouth, UK. : Rowan \& Littlefield, 2014: 34.

14. Ibid. p. 396

15. Ibid. p. 374.

16. Gert B, Culver CM, Clouser KD. Bioethics: A Systematic Approach. New York: Oxford University Press, 2006: 43.

17. Ibid. p. 36.

18. Ibid. p. 208.

19. Ibid. p. 89.

20. Ibid. p. 92

21. Ibid.p. 36

22. Ibid. p. 222.

23. Ibid. p. 43.

24. Ibid.p. 322

25. Ibid. p. 323 .

26. Ibid. p. 310-322.

27. Gibson K. Contrasting role morality and professional morality: implications for practice. J App/ Philos 2003;20(1):s17-29.

28. Hardimon MO. Role obligations. J Philos 1974;91(7):333-63.

29. Simmons AJ. External justifications and institutional roles. J Philos 1996;93(1):28-36.

30. Cane P. Role responsibility. J Ethics 2016;20(1-3):279-98.

31. Baril A. The ethical importance of roles. J Value Inq 2016;50(4):721-34.

32. MacKay D. Standard of care, institutional obligations, and distributive justice. Bioethics 2015;29(4):262-73.

33. Stern RA. "My station and its duties": Social role accounts of obligation in Green and Bradley. In: Ameriks K, ed. The Impact of Idealism. . Philosophy and Natural Sciences. Cambridge University Press, 2013: 1. 299-322.

34. Parsons Tet al. Essays in sociological theory, revised edition. Glencoe, Illinois: The Free Press, 1993: 372.

35. Latham SR. Medical professionalism: a parsonian view. Mt Sinai J Med 2002;69(6):363-9.

36. Tapper A, Millett S. Revisiting the concept of a profession. Research in Ethical Issues in Organisations 2015:13:1-18.

37. Metzger WP. What is a profession. College \& University 1976;52(1):42-55.

38 Ethics and Professionalism Committee-ABMS Professionalism Work Group. ABMS professionalism definition. American Board of medical specialties. Available: http:// www.abms.org/News_and_Events/Media_Newsroom/features/feature_ABMS Professionalism_Definition_LongForm_abms.org_040413.aspx

39. Wear D, Kuczewski MG. The professionalism movement: can we pause? Am J Bioeth 2004;4(2):1-10.

40. Hafferty F, Papadakis M, Sullivan W, et al. The American Board of Medical Specialties Ethics and Professionalism Committee Definition of Professionalism. Chicago, III: American Board of Medical Specialties, 2012.

41. Birden H, Glass N, Wilson I, et al. Defining professionalism in medical education: a systematic review. Med Teach 2014;36(1):47-61. 
42. Parsi K, Sheehan MN. Two Faces of Professionalism. Healing as Vocation: A Medical Professionalism Primer. Langham, MD: Rowman \& Littlefield, 2006.

43. Pavlica P, Barozzi L. Medical professionalism in the new millennium: a physicians' charter. Lancet 2002;359(9305):520-2.

44. Swick HM. Toward a normative definition of medical professionalism. Acad Med 2000;75(6):612-6.

45. Doukas DJ, McCullough LB, Wear S, et al. "The challenge of promoting professionalism through medical ethics and humanities education," . Academic Medicine 2004;88:1624-9.

46. Cohen JJ. Professionalism in medical education, an American perspective: from evidence to accountability. Med Educ 2004;40(7):607-17.

47. Inui TS. A Flag in the Wind: Educating for Professionalism in Medicine. Washington DC: Association of American Medical Colleges, 2003.

48. Stern DT, Papadakis M. The developing physician--becoming a professional. N Eng/ J Med 2006:355(17):1794-9.

49. Irvine D. The Doctors' Tale: Professionalism and Public Trust. Oxon, UK: Raddliffe Publishing Ltd, 2003.

50. Kao A. Professing medicine: Strengthening the ethics and professionalism of tomorrow's physicians (Chicago: American Medical Association, 2001.

51. Cruess SR. Johnston SS, and Cruess rl, professionalism for medicine: opportunities and obligations. Med J Aust 2002;177(4):208-11.

52. Cruess RL, Cruess SR. "Expectations and obligations: professionalism and medicine's social contract with society,". Perspectives in Biology and Medicine 2008;51(4):579-98.

53. Brody H, Doukas D. Professionalism: a framework to guide medical education. Med Educ 2014;48(10):980-7.
54. Karches KE, Sulmasy DPJustice, courage and truthfulness: virtues that medical trainees can and must learn. Fam Med 2016;48(7):511-6.

55. Pelligrino ED, Thomasma DC] . The virtues in medical practice. New York: Oxford University Press, 1993.

56. Wynia MK, Papadakis MA, Sullivan WM, et al. More than a list of values and desired behaviors: a foundational understanding of medical professionalism. Acad Med 2014;89(5):712-4.

57. National Board of Medical Examiners. Embedding professionalism in medical education: assessment as a tool for implementation, 2002. Available: http://www nbme.org/PDF/NBME AAMC ProfessReport.pdf

58. Wilkinson TJ, Wade WB, Knock LD. A blueprint to assess professionalism: results of a systematic review. Acad Med 2009;84(5):551-8.

59. Irby DM. Constructs of professionalism. In: Aurora CO, ed. Medical professionalism best practices: professionalism in the modern era. CO: Alpha Omega Alpha Honor Medical Society, 2017: 9-14.

60. Arnold L. Assessing professional behavior: yesterday, today, and tomorrow. Acad Med 2002;77(6):502-15.

61. Pellegrino ED. Professionalism, profession and the virtues of the good physician. Mt Sinai J Med 2002;69(6):378-84.

62. Rhodes R, Alfandre D. A systematic approach to clinical moral reasoning. Clin Ethics 2007;2(2):66-70.

63 Baumrin BH. "The autonomy of medical ethics: medical science vs. medical practice,". Metaphilosophy 16 1985;2\&3:93-102.

64 Moore GE. Ethics. New York: H. Holt, 1912 